Dementia

and Geriatric

Cognitive Disorders
Dement Geriatr Cogn Disord 2006;21:267-274

DOI: $\underline{10.1159 / 000091433}$
Accepted after revision: July 24, 2005 Published online: February 10, 2006

\title{
A High-Resolution Single Photon Emission Computed Tomography Study of Verbal Recognition Memory in Alzheimer's Disease
}

\author{
Julian N. Trollor ${ }^{a, b}$ Perminder S. Sachdev ${ }^{a, b}$ Walter Haindl ${ }^{c}$ \\ Henry Brodaty ${ }^{a, d}$ Wei Wen ${ }^{a, b}$ Brenda M. Walker ${ }^{c}$ \\ ${ }^{a}$ School of Psychiatry, University of New South Wales, ${ }^{b}$ Neuropsychiatric Institute, Prince of Wales Hospital, \\ Randwick, ${ }^{\mathrm{C}}$ Department of Nuclear Medicine, Prince of Wales and Sydney Children's Hospitals, \\ ${ }^{\mathrm{d} A c a d e m i c ~ D e p a r t m e n t ~ f o r ~ O l d ~ A g e ~ P s y c h i a t r y, ~ P r i n c e ~ o f ~ W a l e s ~ H o s p i t a l, ~ S y d n e y, ~ A u s t r a l i a ~}$
}

\section{Key Words}

Single photon emission computed tomography • Verbal recognition - Alzheimer's disease - Regional cerebral blood flow $\cdot$ Magnetic resonance imaging coregistration

\begin{abstract}
Background: In view of the recent technological advances and its ease of availability, we used single photon emission computed tomography (SPECT) to examine the performance of early Alzheimer's disease (AD) subjects on a verbal recognition memory task. Methods: Eighteen early $A D$ and 10 matched healthy control subjects underwent split-dose ${ }^{99 \mathrm{~m}} \mathrm{Tc}$-HMPAO $\left(\right.$ Ceretec $^{\circledR}$ ) SPECT using a verbal recognition memory and control task. SPECT images co-registered with MRI scans were used to determine relative regional cerebral blood flow (rCBF) changes in regions of interest. Results: In healthy control subjects, verbal recognition increased rCBF in the right occipital region, thalamus, left prefrontal pole, posterior parietal region and cerebellum, and decreased rCBF in the right hippocampus. AD subjects showed bilateral prefrontal, posterior parietal and occipital increases, unilateral increase in the left posterior temporal re-
\end{abstract}

gion, and bilateral reductions in the hippocampus. Although activation was significantly different between the two groups in the right thalamus and left medial prefrontal region, the verbal recognition task did not enhance discrimination between groups. Conclusions: Compared with controls, AD subjects activate a similar but more extensive bilateral network during verbal recognition, possibly reflecting an attempt to compensate for impaired processing.

\section{Introduction}

Using positron emission tomography (PET) Alzheimer disease (AD) subjects have been observed to activate more widespread frontal networks [1,2] or alternate networks [3] during the performance of various cognitive tasks compared to healthy controls. Whilst these observations support the concept of a reduced efficiency of brain function due to neurodegeneration, the diagnostic utility of differential patterns of activation in very early $\mathrm{AD}$ awaits detailed study.

The limited availability of PET scanning has prompted the application of high-resolution single photon emis-

\section{KARGER \\ Fax +4161306 1234 E-Mailkarger@karger.ch} www.karger.com (c) 2006 S. Karger AG, Basel $1420-8008 / 06 / 0214-0267 \$ 23.50 / 0$

Accessible online at:

www.karger.com/dem
Dr. Julian Trollor

Neuropsychiatric Institute, The Prince of Wales Hospital

Randwick, 2031, NSW (Australia)

Tel. +6129382 3763, Fax +61293823774

E-Mail J.Trollor@unsw.edu.au 
sion computed tomography (SPECT) for this purpose [4]. However previous studies are hampered by methodological problems including little or no attempt to control for extraneous cognitive or sensorimotor components of the task, failure to adequately match $\mathrm{AD}$ and healthy control subjects on a variety of measures, and the employment of varying and sometimes crude image analysis methods. Progress in SPECT imaging has prompted a re-examination of this widely available technique in early AD.

Given the salience of verbal memory impairment in $\mathrm{AD}$, we performed split-dose SPECT scans on early AD and healthy control subjects whilst administering a computerised episodic verbal memory task and a control task. We hypothesised that engagement of verbal recognition memory would result in increased regional cerebral blood flow (rCBF) in the left frontotemporal regions in both groups and increased bilaterality of activation in prefrontal regions of interest (ROIs) in AD subjects. We also hypothesised that the increased cognitive demand of the verbal memory task would enhance discrimination of $\mathrm{AD}$ subjects from controls.

\section{Materials and Methods}

\section{Subjects}

We recruited and meticulously screened healthy subjects and subjects with mild AD as previously described [5]. The studies were carried out with the approval of our institutional Ethics Committee and relevant Radiation Safety Committees. Written informed consent was obtained for all subjects, and for AD subjects consent was also obtained from next of kin.

\section{Assessment}

All subjects had detailed neuropsychological assessments, with tests selected to assess the following seven cognitive domains: attention (Mental control, Digit span and Visual span from Wechsler Memory Scale-Revised, WMS-R [6]), verbal memory (Logical memory I, Logical memory II from WMS-R Learning over trials, Trial 6, Recall at delay and Recognition from the Rey Auditory Verbal Learning Test [7]), visual memory (Visual Reproduction I and II from WMS-R), construction (Block Design from the Wechsler Adult Intelligence Scale-Revised, WAIS-R [8]), language (Boston Naming Test [9]), frontal/executive (Similarities from WAIS-R, Controlled Oral Word Association Test and Category Fluency [10], Trail Making Test, part B [11]), speed of information processing (Digit-symbol sub-test from WAIS-R, Trail Making Test, part A [11]).

\section{SPECT and MRI Scans}

SPECT scanning was conducted at a fixed mid-morning timeslot using a Prism 3000XP triple-head gamma camera (Philips Medical Systems, Milpitas, Calif., USA) with low-energy ultra-high resolution fan beam collimators using the following parameters: $128 \times 128$ matrix, 120 steps over 360 degrees, 40 s per step. System resolution (FWHM) was $6.7 \mathrm{~mm}$ at $10 \mathrm{~cm}$. Subjects received an injection of $370 \mathrm{MBq}$ of ${ }^{99 \mathrm{~m}} \mathrm{Tc}-\mathrm{HMPAO}\left(\right.$ Ceretec $^{\circledR}$, Amersham Health, UK) during each of two cognitive tasks designated as 'control' and 'activation'. For the 'control' task, subjects viewed a word and a non-word (nonsense letter string) and were asked to indicate the target (real word) by button press. For the 'activation' task, subjects were shown word pairs in random order and asked to indicate which of the pair was from a pre-learned 10-item word list. Degree of difficulty was standardised for each subject by pre-learning of the target word list to a threshold of six correct words on delayed free recall. For each stimulus the parameters were stimulus duration $2.5 \mathrm{~s}$, interstimulus interval $1.5 \mathrm{~s}$. Task administration commenced $30 \mathrm{~s}$ prior to the radiotracer injection and continued for 3.5 min after injection.

All subjects underwent MRI scan of the brain on a 1.5-tesla Siemens scanner. A 3-D volume acquisition protocol was used, comprising a scout mid-sagittal cut for AC-PC plane alignment followed by coronal FSPGR sequence (TR $12.2 \mathrm{~ms}$, TE $5.3 \mathrm{~ms}$, FOV $25 \mathrm{~cm}$, matrix $256 \times 256$, slice thickness $1.5 \mathrm{~mm}$, no gap).

\section{Analysis}

SPECT and MRI images were transferred to a Silicon Graphics ${ }^{\circledR}$ Indy ${ }^{\circledR}$ R5000 workstation, reconstructed and displayed using ANALYZE ${ }^{\circledR}$ software (Biomedical Imaging Resource, Mayo Clinic, Rochester, Minn., USA). Multiple standardised anatomical ROIs were delineated on each subject's MRI scan: prefrontal cortex (dorsolateral, medial, orbital, prefrontal pole), temporal cortex (anterior and posterior), hippocampus, parietal cortex (anterior and posterior), occipital cortex, cingulate gyrus (anterior, body and posterior), basal ganglia (caudate, putamen and globus pallidus) and thalamus. Further details of this protocol are available on request.

Co-registration of SPECT and MRI images was performed using the Automated Multimodality Image Registration software package developed by Ardekani et al. [12]. Counts for each individual ROI were obtained from SPECT data representing the "control' and the 'recognition' task and normalised to whole brain counts.

\section{Neuropsychological Data}

Individual test scores were expressed as an age-scaled z-score, using Mayo Clinic norms [13-19]. Indices of regional neuropsychological function were derived by addition of test z-scores within the seven cognitive domains.

\section{Statistical Analysis}

All statistical analyses were performed utilising the Statistical Package for the Social Sciences (SPSS Inc. 1989-1999) software for Windows, version 10.0.5. In order to minimise the risk of a type I error, functionally related ROIs from both right and left hemisphere were considered together as a collection of dependent variables comprising six 'composite' regions (prefrontal, temporal, parietal, occipital, cingulate and subcortical). Bonferroni correction was applied to correct for multiple comparisons.

A process conceptually akin to 'cognitive subtraction' was used to identify changes due to the verbal recognition memory component of the recognition task. A $2 \times 2$ within-subject repeated measures analysis of variance was used to establish the effects of verbal recognition. Asymmetry of activation effect was explored in each subject group using repeated measures analysis of variance. Comparison of activation effects was evaluated using both descriptive 

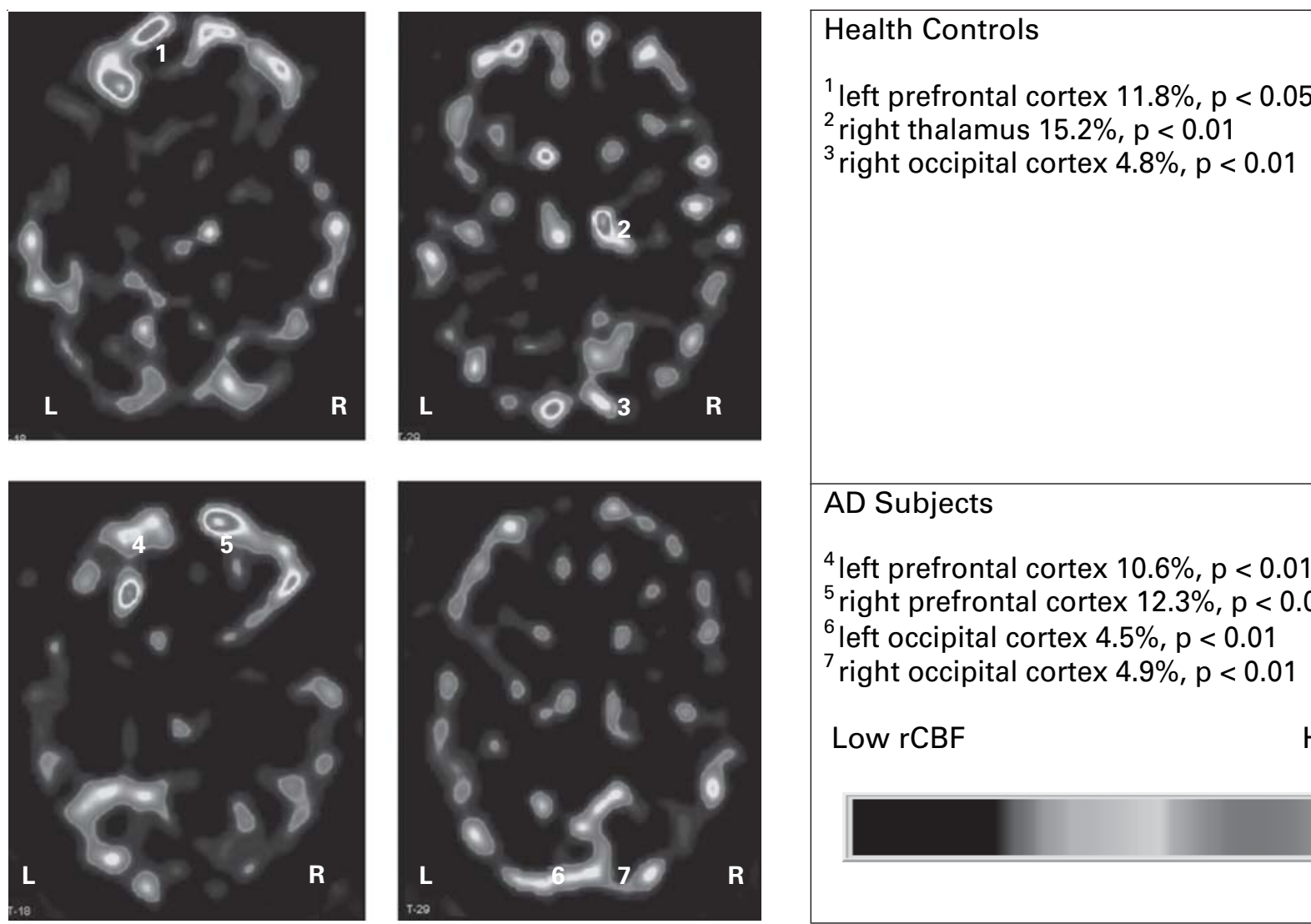

\section{AD Subjects}

${ }^{4}$ left prefrontal cortex $10.6 \%, p<0.01$

${ }^{5}$ right prefrontal cortex $12.3 \%, p<0.001$

${ }^{6}$ left occipital cortex 4.5\%, p $<0.01$

${ }^{7}$ right occipital cortex 4.9\%, p $<0.01$

Low rCBF

High rCBF

Fig. 1. Axial subtraction images showing $\mathrm{rCBF}$ increases due to the task in health control subjects (upper panels) and AD subjects (lower panels) at the level of the orbital prefrontal cortex (left panels) and basal ganglia (right panels). $\mathrm{p}$ values shown after correction for multiple comparisons.

(number of regions showing significant activation) and quantitative $(2 \times 2$ repeated measures multivariate analysis of variance $)$ methods. Discriminant function analysis was used to establish which region or regions were best able to discriminate the $\mathrm{AD}$ from the healthy control group, both during performance of the control and recognition task. Bivariate correlation analysis (using Pearson correlation coefficients and two-tailed tests of significance) was used to determine the strength of association between $\mathrm{rCBF}$ activation effects and the independent variables of age, task performance and neuropsychological indices.

\section{Results}

\section{Sociodemographic Variables and Task Performance}

The two groups were adequately matched for age, sex ratio, estimated premorbid intellectual function and years of education (table 1). AD subjects had dementia of mild severity as indicated by MMSE. The control task was performed proficiently ( $>95 \%$ accuracy) by both healthy controls and AD subjects, but the recognition task was performed less accurately $(\mathrm{p}<0.05)$ and more slowly $(\mathrm{p}<0.001)$ by the AD subjects (table 2$)$.

\section{Cerebral Blood Flow Change with Verbal Recognition}

In healthy controls, there was an effect of verbal recognition on $\mathrm{rCBF}$ for the parietal $[\mathrm{F}(4,6)=13.47, \mathrm{p}<$ $0.01]$ and occipital $[\mathrm{F}(2,8)=6.51, \mathrm{p}<0.05]$ composite regions. Task-related changes in $\mathrm{rCBF}$ in the prefrontal $[F(8,2)=10.47, p=0.090]$ and cingulate $[F(6,4)=4.63$, $\mathrm{p}=0.080]$ composite regions approached significance. For individual ROIs, statistically significant increases in rCBF were apparent in the right occipital, right thalamic, left prefrontal pole, left posterior parietal and cerebellar ROIs (figure 1, top panels; tables 3 and 4). A statistically significant reduction in $\mathrm{rCBF}$ was apparent in the right hippocampus. No asymmetry of activation was demonstrable.

In $\mathrm{AD}$ subjects, an effect of verbal recognition was noted on $\mathrm{rCBF}$ in the prefrontal $[\mathrm{F}(8,9)=10.78, \mathrm{p}<0.01]$, 
Table 1. Sociodemographic profile of $\mathrm{AD}$ $(\mathrm{n}=18)$ and healthy control $(\mathrm{n}=10)$ subjects

\begin{tabular}{|c|c|c|c|c|c|c|}
\hline & \multicolumn{2}{|l|}{ AD subjects } & \multicolumn{2}{|l|}{ Controls } & \multirow[t]{2}{*}{$\mathrm{t}$} & \multirow[t]{2}{*}{$\mathrm{p}$ value } \\
\hline & mean (median) & SD & mean (median) & SD & & \\
\hline Age, years & 71.4 & 8.4 & 68.9 & 5.8 & 0.9 & 0.354 \\
\hline Sex ratio $(M: F)$ & $11: 7$ & & $6: 4$ & & $0.009^{\mathrm{a}}$ & 0.923 \\
\hline Estimated full-scale IQ & 103.1 & 9.6 & 101.3 & 7.2 & 0.6 & 0.582 \\
\hline Education, years & 11.4 & 4.2 & 11.8 & 2.3 & -0.3 & 0.768 \\
\hline MMSE score & $23.7(25.0)$ & 3.7 & $29.5(29.8)$ & 0.7 & -6.3 & $0.000 *$ \\
\hline $\begin{array}{l}\text { Hachinski Ischaemia } \\
\text { Scale }\end{array}$ & 0.6 & 0.6 & 0.5 & 0.7 & 0.2 & 0.837 \\
\hline
\end{tabular}

Significance level two-tailed: $* \mathrm{p}<0.001$. Degrees of freedom for $\mathrm{t}$ tests $=26$. ${ }^{\mathrm{a}} \chi^{2}$ analysis.

Table 2. Performance and anxiety ratings during the recognition task (mean $\pm \mathrm{SD}$ )

\begin{tabular}{|c|c|c|c|c|c|c|c|c|}
\hline & \multicolumn{4}{|l|}{ Control task } & \multicolumn{4}{|c|}{ Recognition task } \\
\hline & $\mathrm{AD}$ & controls & $\mathrm{t}$ & $\mathrm{p}$ & $\mathrm{AD}$ & controls & $\mathrm{t}$ & $\mathrm{p}$ \\
\hline Task score, $\%$ correct & $95.3 \pm 12.2$ & $100 \pm 0$ & -1.2 & 0.232 & $88.4 \pm 13.3$ & $99.5 \pm 0.9$ & -2.60 & $0.015^{*}$ \\
\hline Reaction time, ms & $972 \pm 299$ & $789 \pm 188$ & 1.7 & 0.095 & $1,558 \pm 227$ & $1,146 \pm 242$ & 4.44 & $0.000 * *$ \\
\hline
\end{tabular}

Analysis performed with a t test for independent samples, using two-tailed $\mathrm{p}$ values. Significant levels: ${ }^{*} \mathrm{p}<0.05 ; * * \mathrm{p}<0.001$. Degrees of freedom for control task $=26$, for recognition task $=25$.

temporal $[\mathrm{F}(6,11)=8.29, \mathrm{p}<0.01]$, parietal $[\mathrm{F}(4,13)=$ $3.61, \mathrm{p}<0.05]$, occipital $[\mathrm{F}(2,15)=13.93, \mathrm{p}<0.001]$ and cingulate $[\mathrm{F}(6,11)=4.18, \mathrm{p}<0.05]$ composite regions. For individual regions, there was a statistically significant increase in $\mathrm{rCBF}$ bilaterally in the prefrontal, posterior parietal and occipital ROIs (figure 1, bottom panels). Significant increases in $\mathrm{rCBF}$ were also observed in the left posterior temporal and cerebellar ROIs. Reduction in hippocampal rCBF was apparent in the hippocampus bilaterally. Again, no asymmetry of activation was demonstrable. There were no significant interaction effects of activation with age or task performance.

\section{Correlates of $r C B F$ Changes with Verbal Recognition}

For healthy subjects, a relationship between task errors and activation effects in the right posterior temporal lobe was observed $(r=0.67, p<0.05)$, suggesting that better performance on the task was associated with less activation in this region. A negative correlation was observed between activation in the right posterior temporal lobe and attention index $(r=-0.73, p<0.05)$, suggesting better performance on this index was associated with less activation in this ROI. Negative correlation was apparent between deactivation in the right hippocampus and most neuropsychological indices, but only reached significance for the verbal memory index $(r=-0.73, p<0.05)$, suggesting that better neuropsychological performance was associated with more efficient deactivation of the hippocampus.

For AD subjects, significant negative correlations were observed between reaction time and $\mathrm{rCBF}$ activation in the left dorsolateral prefrontal ROI $(\mathrm{r}=-0.57, \mathrm{p}<0.05)$ as well as the right posterior parietal ROI $(r=-0.51, p<$ 0.05 ), suggesting that activation in these ROIs increased as patients experienced increasing difficulty with the task. Positive correlations were observed between rCBF activation and neuropsychological performance for the left posterior temporal lobe and verbal memory index $(\mathrm{r}=$ $0.64, p<0.05)$, left posterior temporal lobe and frontal index $(r=0.55, p<0.05)$, right posterior parietal lobe and verbal memory $(r=0.54, p<0.05)$ and right posterior parietal lobe and attention $(r=0.50, p<0.05)$. The direction of these relationships suggested that in these areas, more intact neuropsychological function was associated with greater ability to activate in response to cognitive demand. 
Table 3. Verbal recognition effects in healthy control subjects and AD subjects in right hemisphere ROIs (univariate statistics from repeated-measures analysis)
Table 4. Verbal recognition effects in healthy control and AD subjects in left hemisphere ROIs (univariate statistics from repeated-measures analysis)

\begin{tabular}{|c|c|c|c|c|}
\hline \multirow[t]{2}{*}{ ROI } & \multicolumn{2}{|c|}{ Healthy controls } & \multicolumn{2}{|c|}{ AD subjects } \\
\hline & $\mathrm{F}$ & $\%$ activation & $\mathrm{F}$ & $\%$ activation \\
\hline Medial prefrontal & 0.93 & -3.5 & 1.03 & -1.4 \\
\hline Dorsolateral prefrontal & 1.55 & 3.2 & 1.09 & -1.4 \\
\hline Orbital prefrontal & 0.59 & -1.3 & 5.40 & -4.4 \\
\hline Prefrontal pole & 7.30 & 13.1 & 64.41 & $12.3^{* * *}$ \\
\hline Hippocampus & 15.41 & $-11.7^{*}$ & 20.55 & $-9.3^{* *}$ \\
\hline Anterior temporal & 2.63 & 4.7 & 1.23 & 1.7 \\
\hline Posterior temporal & 9.53 & $3.6^{\#}$ & 0.83 & 1.5 \\
\hline Anterior parietal & 0.49 & 1.3 & 0.00 & 0 \\
\hline Posterior parietal & 5.30 & 6.3 & 10.19 & $3^{*}$ \\
\hline Occipital & 12.77 & $4.8^{*}$ & 20.04 & $4.9^{* * *}$ \\
\hline Anterior cingulate & 2.43 & -7.8 & 3.78 & -3.6 \\
\hline Cingulate body & 0.10 & -1.5 & 1.30 & 3.2 \\
\hline Posterior cingulate & 0.56 & -1.8 & 0.01 & -0.2 \\
\hline Caudate & 0.95 & 5.7 & 0.58 & 3.1 \\
\hline Putamen & 0.48 & 3.3 & 2.87 & 4.7 \\
\hline Globus pallidus & 0.06 & -1 & 0.27 & -1.9 \\
\hline Thalamus & 26.05 & $15.2^{* * *}$ & 0.04 & 0.6 \\
\hline
\end{tabular}

Degrees of freedom for healthy controls $=1,9$; for $\mathrm{AD}$ subjects $=1,16 . \mathrm{F}=$ Variance ratio. ${ }^{\#}$ Corrected $\mathrm{p}$ value $<0.1 ; *$ corrected $\mathrm{p}$ value $<0.05$; ** corrected $\mathrm{p}$ value $<0.01$; $* * *$ corrected $\mathrm{p}$ value $<0.001$. Significance levels defined after Bonferroni correction for each composite region as follows: prefrontal and subcortical ROIs $\alpha_{\text {Bonf }}=\alpha / 8$; temporal and cingulate ROIs $\alpha_{\text {Bonf }}=\alpha / 6$; parietal ROIs $\alpha_{\text {Bonf }}=\alpha / 4$; occipital ROIs $\alpha_{\text {Bonf }}=\alpha / 2$.

\begin{tabular}{|c|c|c|c|c|}
\hline \multirow[t]{2}{*}{ ROI } & \multicolumn{2}{|c|}{ Healthy controls } & \multicolumn{2}{|c|}{ AD subjects } \\
\hline & $\mathrm{F}$ & $\%$ activation & $\mathrm{F}$ & $\%$ activation \\
\hline Medial prefrontal & 3.74 & 3 & 1.88 & -2.3 \\
\hline Dorsolateral prefrontal & 0.01 & 0.2 & 8.75 & $4.7^{\#}$ \\
\hline Orbital prefrontal & 1.09 & -2.5 & 0.20 & -0.7 \\
\hline Prefrontal pole & 12.76 & $11.8^{*}$ & 18.6 & $10.6^{* *}$ \\
\hline Hippocampus & 1.78 & -5.7 & 11.3 & $-6.6^{*}$ \\
\hline Anterior temporal & 2.88 & 6.4 & 7.64 & $3.2^{\#}$ \\
\hline Posterior temporal & 8.08 & 7 & 12.3 & $4.8^{*}$ \\
\hline Anterior parietal & 5.00 & 2 & 1.66 & 0.8 \\
\hline Posterior parietal & 21.39 & $7.8^{* * *}$ & 10.7 & $3.5^{*}$ \\
\hline Occipital & 4.01 & 6.8 & 18.3 & $4.5^{* *}$ \\
\hline Anterior cingulate & 4.38 & -6.8 & 6.88 & -10.7 \\
\hline Cingulate body & 0.53 & -2.6 & 1.43 & 3.7 \\
\hline Posterior cingulate & 0.07 & -1.1 & 2.55 & 2.9 \\
\hline Caudate & 6.17 & 13.4 & 0.35 & 2.6 \\
\hline Putamen & 0.12 & -1.6 & 0.41 & 1.5 \\
\hline Globus pallidus & 1.73 & -6.6 & 1.18 & -3 \\
\hline Thalamus & 2.91 & 6.3 & 2.59 & 4.5 \\
\hline Cerebellum & 8.93 & $9.0^{*}$ & 40.4 & $6.6 * * *$ \\
\hline
\end{tabular}

Degrees of freedom for healthy controls $=1,9$; for $\mathrm{AD}$ subjects $=1,16 . \mathrm{F}=$ Variance ratio. ${ }^{\#}$ Corrected $\mathrm{p}$ value $<0.1$; * corrected $\mathrm{p}$ value $<0.05$; ** corrected $\mathrm{p}$ value $<0.01$; $* * *$ corrected $\mathrm{p}$ value $<0.001$. Significance levels defined after Bonferroni correction for each composite region as follows: prefrontal and subcortical ROIs $\alpha_{\text {Bonf }}=\alpha / 8$; temporal and cingulate ROIs $\alpha_{\text {Bonf }}=\alpha / 6$; parietal ROIs $\alpha_{\text {Bonf }}=\alpha / 4$; occipital ROIs $\alpha_{\text {Bonf }}=\alpha / 2$. 
Comparison of Effects of Verbal Recognition in AD

Subjects and Healthy Controls

Similar patterns of activation were seen in both subject groups in the prefrontal poles bilaterally, left posterior parietal lobe, right occipital lobe and cerebellum. There was a greater number of regions in which significant or near significant $(p<0.1)$ level changes due to the verbal recognition task were observed in AD subjects (11 regions) compared with healthy control subjects (7 regions). After covarying for task performance, there was a significantly larger increase in $\mathrm{rCBF}$ in the right thalamus in the controls $(15.2 \%)$ compared with $\mathrm{AD}$ subjects $(0.6 \%)$ $[\mathrm{F}(1,22)=9.51, \mathrm{p}<0.05]$. In the left medial prefrontal region controls showed an increase in $\mathrm{rCBF}$ of $3.0 \%$ but $\mathrm{AD}$ subjects showed a decrease of $-2.3 \%[\mathrm{~F}(1,22)=9.10$, $\mathrm{p}<0.05]$.

\section{Effect of the Cognitive Task on the Prediction of Group Membership}

For the control task, rCBF in the left prefrontal pole achieved the best classification of cases (correctly classified $85.7 \%$ of subjects, at specificity $90 \%$ and sensitivity 83.3\%). During the control task, the best performance of any temporal or parietal region was the right posterior temporal lobe (correctly classified $78.6 \%$, with specificity of $90 \%$ and sensitivity $72.2 \%$ ). Against expectations, the ability of rCBF in these ROIs to predict group membership was poorer for the recognition task than for the control task. The region to show the best classification statistic during performance of the verbal recognition task was the right dorsolateral prefrontal region (77.8\% correct classification, at specificity of $90 \%$ and sensitivity of $70.6 \%$ ). Combinations of regions were entered into the analysis but failed to improve classification statistics.

\section{Discussion}

\section{Effects of the Verbal Recognition Task}

Previous work has emphasised asymmetry $(\mathrm{R}>\mathrm{L})$ of prefrontal activation $[20,21]$ in retrieval tasks. We found bilateral activation in the prefrontal poles of both our AD and healthy control subjects. Recent work suggests that the usual asymmetry observed in a variety of retrieval tasks in younger subjects may not be present in the elderly $[22,23]$. Furthermore, other recognition paradigms employed in studies comparing AD subjects with healthy elderly controls have often shown reversed asymmetry of retrieval processes $(L>R)[3,24,25]$, presumably in part as a function of the age of the control subjects. The lack of prefrontal asymmetry arising during verbal recognition in our healthy control subjects may therefore represent age-dependent increases in compensatory allocation of other frontal networks in order to maintain performance under taxing conditions.

Posterior parietal activations were observed in healthy controls and $\mathrm{AD}$ subjects. Activation of biparietal regions can be a feature of recognition per se rather than being modality specific $[26,27]$. Activation of the lateral parietal cortex is thought to be more a feature of recognition, whereas medial structures such as the precuneus may be activated by the actual 'recovery' from episodic memory $[28,29]$. The task employed for this study, whilst having largely a recognition format, cannot be considered to be devoid of effortful 'recovery' of material from episodic stores. Thus it is possible that activation represented in this study reflects a combination of these processes.

The prominent bilateral occipital lobe activation was unexpected. A small number of studies have commented on occipito-parietal [30] or occipital [31,32] increases in brain activity during performance of verbal episodic memory tasks, but coherent explanations for its occurrence are lacking. In light of a previous PET study in which successful performance on a memory task was associated with bilateral occipital activation [33], it is possible that our finding represents a shift to more posterior networks in order to compensate for age-related and ADrelated frontal lobe dysfunction. Alternatively, as activation of the extrastriate cortex is a selective feature of visual [34] processing of words and non-words, it is possible that discrepancy in pre-lexical processing demands between our control and recognition tasks may also explain the occipital activation.

Cerebellar activation was marked in this study. This is not surprising, given the proposed role of this structure in a variety of cognitive processes [35], including the recall [36] and recognition [37] tasks. The role of the cerebellum in episodic memory function is unlikely to be specifically linked to memory per se. Rather, the cerebellum has been proposed to have an 'executive' role in co-ordination and maintenance of the retrieval process [36].

Right unilateral thalamic activation was seen as a prominent feature of response to the verbal recognition task in control subjects, but was absent in AD subjects. Previous studies have documented bilateral [38], left unilateral [30] or right unilateral [22] activation of the thalamus with episodic memory tasks. Correlates of thalamic activation in this and previous studies have remained obscure. 
In this study, substantial hippocampal deactivation was apparent in healthy control and AD subjects. The consistency of the deactivation across subjects as well as its magnitude argues against this being artefactual. Hippocampal deactivation has previously been observed in AD subjects undergoing tests of cued verbal recall [39]. Temporal lobe deactivations have been interpreted as an efficiency-based strategy of inhibition mediated by the prefrontal cortex [40]. The consistent negative correlation between activation effect and neuropsychological test scores in healthy control subjects observed in the right hippocampus would be consistent with this notion.

\section{Utility of Cognitive Stress}

With the exception of a small number of regions (bilateral posterior parietal and right thalamic ROIs), the more complex verbal recognition task failed to enhance between-group $\mathrm{rCBF}$ differences or the discriminant function. These results suggest that there is a significant flaw in the notion that a 'cognitive stress test' increases likelihood of discriminating healthy from diseased states. The ability of episodic memory tasks to exaggerate the temporo-parietal perfusion or metabolic deficits in $\mathrm{AD}$ subjects has not been convincingly demonstrated. There is only one earlier report of this phenomenon in $\mathrm{AD}$ subjects [41], utilising an olfactory memory task, but the interpretability is reduced by the lack of an adequate control or reference condition. Although the relatively poor resolution of SPECT may limit its ability to detect such a phenomenon, this was not the case for our study in which the rCBF deficits appeared to be ameliorated by the performance of a more demanding task.

\section{Limitations}

Our limitations included the lack of ability to incorporate a resting condition, the time-consuming nature of the manual ROI method and its presuppositions regarding areas of interest, and the small sample size relative to the number of variables which increases the risk of a type II error.

\section{Conclusions}

The present study demonstrates the utility of high-resolution SPECT in cognitive activation experiments, with the information obtained being comparable to PET activation studies of $A D$. The study provides evidence that $\mathrm{AD}$ subjects activate and deactivate some task-specific networks with some similarity to healthy subjects in response to verbal recognition. However, AD subjects demonstrate bilaterality of activation and deactivation in many key areas. This observation is in keeping with the adaptive capacity of the impaired brain as it attempts to optimise function by extending the allocation of resources for a particular cognitive task. It seems unlikely that the strategy of memory activation will be of clinical value in assisting in discrimination of very early cases of dementia from normal ageing. However, the technique allows the study of the interaction between discrete brain activations and disease effects, hence helping build an understanding of the functional neuropsychology of $\mathrm{AD}$ or other dementia syndromes.

\section{References}

$>1$ Becker JT, Mintun MA, Aleva K, Wiseman MB, Nichols T, Dekosky ST: Compensatory reallocation of brain resources supporting verbal episodic memory in Alzheimer's disease. Neurology 1996;46:692-700.

2 Woodard JL, Grafton ST, Votaw JR, Green RC, Dobraski ME, Hoffman JM: Compensatory recruitment of neural resources during overt rehearsal of word lists in Alzheimer's disease. Neuropsychology 1998;12:491-504.

- 3 Stern Y, Moeller JR, Anderson KE, Luber B, Zubin NR, DiMauro AA, Park A, Campbell CE, Marder K, Bell K, Van Heertum R, Sackeim HA: Different brain networks mediate task performance in normal aging and $\mathrm{AD}$ : defining compensation. Neurology 2000;55: 1291-1297.
4 Cardebat D, Demonet JF, Puel M, Agniel A, Viallard G, Celsis P: Brain correlates of memory processes in patients with dementia of Alzheimer's type: a SPECT Activation Study. J Cereb Blood Flow Metab 1998;18:457-462.

5 Trollor JN, Sachdev PS, Haindl W, Brodaty H, Wen W, Walker BM: Regional cerebral blood flow deficits in mild Alzheimer's disease using high resolution single photon emission computerized tomography. Psychiatry Clin Neurosci 2005;59:280-290.

6 Wechsler D: Wechsler Memory Scale-Revised (WMS-R): San Antonio, The Psychological Corporation, 1987

7 Rey A: L'examen clinique en psychologie. Paris, Presse Universitaire de France, 1958

8 Wechsler D: Wechsler Adult Intelligence ScaleRevised (WAIS-R). New York, Psychological Corporation, 1981.
9 Kaplan EF, Goodglass H, Weintraub S: The Boston Naming Test, ed 2. Philadelphia, Lea \& Febiger, 1983.

10 Spreen O, Benton AL: Neurosensory Centre Comprehensive Examination for Aphasia. Victoria, University of Victoria Neuropsychology Laboratory, 1977.

11 Reitan RM, Wolfson D: The Halstead-Reitan Neuropsychological Test Battery. Tucson, Neuropsychology Press, 1985.

-12 Ardekani BA, Braun M, Hutton BF, Kanno I, Iida $\mathrm{H}$ : A fully automatic multimodality image registration algorithm. J Comput Assist Tomogr 1995; 19:615-623.

13 Mack WJ, Freed DM, Williams BW, Henderson VW: Boston Naming Test: shortened versions for use in Alzheimer's disease. J Gerontol 1992;47:154-158. 
14 Spreen O, Strauss E: A Compendium of Neuropsychological Tests. Administration, Norms and Commentary. Oxford, Oxford University Press, 1998.

15 Tombaugh TN, et al: Normative data for the Controlled Oral Word Association Test. Personal communication, 1996; in Spreen O, Strauss E (eds): A Compendium of Neuropsychological Tests. Administration, Norms and Commentary, ed 2. New York, Oxford University Press, 1998, pp 447-464.

16 Ivnik RJ, Malec JF, Smith GE, Tangalos EG, Petersen RC, Kokmen E, Kurland LT: Mayo's Older Americans Normative Studies: WMS-R norms for ages 56 to 94 . Clin Neuropsychol 1992;6(suppl):49-82.

17 Ivnik RJ, Malec JF, Smith GE, Tangalos EG, Petersen RC, Kokmen E, Kurland LT: Mayo's Older Americans Normative Studies: WAIS-R norms for ages 56 to 97 . Clin Neuropsychol 1992;6(suppl):1-30.

18 Ivnik RJ, Malec JF, Smith GE, Tangalos EG, Petersen RC: Neuropsychological tests' norms above age 55: COWAT, BNT, MAE Token, WRAT-R Reading, AMNART, STROOP, TMT, and JLO. Clin Neuropsychol 1996;10: 262-278.

19 Ryan JJ, Paolo AM: A screening procedure for estimating premorbid intelligence in the elderly. Clin Neuropsychol 1992;6:53-62.

-20 Tulving E, Kapur S, Craik FI, Moscovitch M, Houle S: Hemispheric encoding/retrieval asymmetry in episodic memory: positron emission tomography findings. Proc Natl Acad Sci USA 1994;91:2016-2020.

-21 Desgranges B, Baron JC, Eustache F: The functional neuroanatomy of episodic memory: the role of the frontal lobes, the hippocampal formation, and other areas. Neuroimage 1998; 8 : 198-213.

-22 Madden DJ, Turkington TG, Provenzale JM, Denny LL, Hawk TC, Gottlob LR, Coleman RE: Adult age differences in the functional neuroanatomy of verbal recognition memory. Hum Brain Mapp 1999; 7:115-135.

- 23 Cabeza R, Anderson ND, Houle S, Mangels JA, Nyberg L: Age-related differences in neural activity during item and temporal-order memory retrieval: a positron emission tomography study. J Cogn Neurosci 2000;12:197-206.
24 Miller JD, de Leon MJ, Ferris SH, Kluger A, George AE, Reisberg B, Sachs HJ, Wolf AP: Abnormal temporal lobe response in Alzheimer's disease during cognitive processing as measured by 11C-2-deoxy- $D$-glucose and PET. J Cereb Blood Flow Metab 1987;7:248-251.

25 Burke C, Batchelor J, Schwartz RS, Snars J, Gordon E, Yiannikas C: Regional cerebral blood flow during memory recognition and neuropsychological performance in patients referred for investigation of dementia. Clin Exp Neurol 1993;30:90-97.

26 Tulving E, Kapur S, Markowitsch HJ, Craik FI, Habib R, Houle S: Neuroanatomical correlates of retrieval in episodic memory: auditory sentence recognition. Proc Natl Acad Sci USA 1994;91:2012-2015.

27 Haxby JV, Ungerleider LG, Horwitz B, Maisog JM, Rapoport SI, Grady CL: Face encoding and recognition in the human brain. Proc Natl Acad Sci USA 1996;93:922-927.

28 Nyberg L: Mapping episodic memory. Behav Brain Res 1998;90:107-114.

29 Wiggs CL, Weisberg J, Martin A: Neural correlates of semantic and episodic memory retrieval. Neuropsychologia 1999;37:103-118.

- 30 Cabeza R, Grady CL, Nyberg L, McIntosh AR, Tulving E, Kapur S, Jennings JM, Houle S, Craik FI: Age-related differences in neural activity during memory encoding and retrieval: a positron emission tomography study. J Neurosci 1997;17:391-400.

31 Nyberg L, Tulving E, Habib R, Nilsson LG, Kapur S, Houle S, Cabeza R, McIntosh AR: Functional brain maps of retrieval mode and recovery of episodic information. Neuroreport 1995; 7:249-252.

32 Petrides M, Alivisatos B, Evans AC: Functional activation of the human ventrolateral frontal cortex during mnemonic retrieval of verbal information. Proc Natl Acad Sci USA 1995;92: 5803-5807.
33 Hazlett EA, Buchsbaum MS, Mohs RC, Spiegel-Cohen J, Wei TC, Azueta R, Haznedar MM, Singer MB, Shihabuddin L, Luu-Hsia C, Harvey PD: Age-related shift in brain region activity during successful memory performance. Neurobiol Aging 1998;19:437-445.

34 Petersen SE, Fox PT, Snyder AZ, Raichle ME: Activation of extrastriate and frontal cortical areas by visual words and word-like stimuli. Science 1990;249:1041-1044.

35 Leiner HC, Leiner AL, Dow RS: Cognitive and language functions of the human cerebellum. Trends Neurosci 1993;16:444-447.

36 Andreasen NC, O'Leary DS, Paradiso S, Cizadlo T, Arndt S, Watkins GL, Ponto LL, Hichwa $\mathrm{RD}$ : The cerebellum plays a role in conscious episodic memory retrieval. Hum Brain Mapp 1999;8:226-234.

37 Moscovitch C, Kapur S, Kohler S, Houle S: Distinct neural correlates of visual long-term memory for spatial location and object identity: a positron emission tomography study in humans. Proc Natl Acad Sci USA 1995;92: 3721-3725.

38 Shallice T, Fletcher P, Frith CD, Grasby P, Frackowiak RS, Dolan RJ: Brain regions associated with acquisition and retrieval of verbal episodic memory. Nature 1994;368:633635.

39 Backman L, Andersson JR, Nyberg L, Winblad $\mathrm{B}$, Nordberg A, Almkvist O: Brain regions associated with episodic retrieval in normal aging and Alzheimer's disease. Neurology 1999; 52:1861-1870.

40 Nyberg L, McIntosh AR, Cabeza R, Nilsson LG, Houle S, Habib R, Tulving E: Network analysis of positron emission tomography regional cerebral blood flow data: ensemble inhibition during episodic memory retrieval. J Neurosci 1996;16:3753-3759.

41 Buchsbaum MS, Kesslak JP, Lynch G, Chui H, Wu J, Sicotte N, Hazlett E, Teng E, Cotman CW: Temporal and hippocampal metabolic rate during an olfactory memory task assessed by positron emission tomography in patients with dementia of the Alzheimer type and controls. Preliminary studies. Arch Gen Psychiatry 1991;48:840-847. 